\title{
Semantic and phonological influences on the processing of words and pseudohomophones
}

\author{
MARK YATES, LAWRENCE LOCKER, JR., and GREG B. SIMPSON \\ University of Kansas, Lawrence, Kansas
}

\begin{abstract}
In two experiments, we investigated the relationship between semantics and phonology in the lexical decision task. In the first experiment, lexical decisions to words with large semantic neighborhoods were faster than those to words with sparse semantic neighborhoods. Conversely, this effect of semantic neighborhood was reversed for pseudohomophones (e.g., nale). That is, pseudohomophones based on words with large semantic neighborhoods took longer to reject than did those based on words with sparse semantic neighborhoods. In the second experiment, we found the magnitude of the semantic neighborhood effect for words to be a function of nonword foil type. Taken together, these results indicate that semantic neighborhood size affects processing of both words and pseudohomophones, and that the effect of semantic neighborhood size for words is more pronounced when pseudohomophone foils are employed. These effects are discussed in terms of a model in which the orthographic, phonological, and semantic systems are fully interactive.
\end{abstract}

In the area of visual word recognition, one of the most debated topics concerns the degree to which phonological codes play a role in the recognition of letter strings. As evidence that phonology does play a role in the lexical decision task, researchers have shown that nonword response latencies are longer to pseudohomophones (e.g., nale) than to orthographically matched pseudowords (e.g., nalp; Coltheart, Davelaar, Jonasson, \& Besner, 1977; Fera \& Besner, 1992; McCann, Besner, \& Davelaar, 1988; Rubenstein, Lewis, \& Rubenstein, 1971; Seidenberg, Petersen, MacDonald, \& Plaut, 1996), implying that the pseudohomophone accesses the representation of its base word (e.g., nail), and that this base word representation slows the processing of the pseudohomophone. Because the pseudohomophone effect has become central to models of word recognition (Ziegler, Jacobs, \& Klüppel, 2001), it is critical that we understand fully the processes underlying the effect.

It is not clear, however, exactly what properties of the base word affect processing of pseudohomophones. Two potential representations are usually implicated. The first and most obvious candidate is simply the phonological representation itself. According to this account, pseudohomophones activate the phonological representation of their base words, and because the phonological representation of a pseudohomophone perfectly matches the phonology of an actual word, "no" latencies toward pseudohomophones are increased. Thus, on this account, it is

The authors thank Jay Rueckl, Michael Masson, Michael Harm, and an anonymous reviewer for their helpful comments and criticisms on an earlier version of this manuscript. Correspondence concerning this article should be addressed to M. Yates, 1415 Jayhawk Blvd., 426 Fraser Hall, Lawrence, KS 66045-7556(e-mail: myates@ukans.edu). simply the phonological form of the pseudohomophone that slows processing. This purely phonological account of the pseudohomophoneeffect is the most common (Ziegler et al., 2001). However, another possibility is that a pseudohomophone activates the semantic representation of its base word. On this account, a pseudohomophone activates the phonological representation of its base word, which in turn activates the word's semantic representation. Thus, "no" latencies to a pseudohomophone are longer because the semantic activation associated with the base word incorrectly indicates that the pseudohomophone is a word. The difference between these two accounts is that the latter posits an extra step (i.e., from phonology to semantics).

One can understand the semantic account of the pseudohomophone effect by considering a framework within which the orthographic, phonological, and semantic levels are fully interactive (see, e.g., Pexman \& Lupker, 1999; Seidenberg \& McClelland, 1989). In this framework, the phonological representation of a pseudohomophone activates the semantic representation of its base word because of the match between the phonology of the pseudohomophone and that of the base word. With this increased semantic activation, a pseudohomophone will appear more wordlike, and the "no" latency will increase. Of course, these accounts of the pseudohomophone effect (i.e., the phonological and the semantic accounts) are not necessarily mutually exclusive. It is possible that the processing of pseudohomophones is affected by both factors (i.e., by both the phonological and semantic forms). Nevertheless, in the present research, we tested the hypothesis that semantics influences the processing of pseudohomophones in the lexical decision task.

Some evidence that pseudohomophones activate the semantic representation of their base words comes from 
the semantic verification task (Van Orden, 1987; Van Orden, Johnston, \& Hale, 1988). When given a semantic category (e.g., the name of a flower) and asked to decide whether or not a letter string is a member of that category, participants make more false positives when the letter string is a pseudohomophone that has a base word that is a member of the category (e.g., roze) than they do when it is a pseudoword (e.g., rofe). This result seems to indicate that pseudohomophones are able to activate the semantic representations of their base words, but it does not follow that the pseudohomophone effect in the lexical decision task has a similar semantic locus. The verification task necessarily involves activating the semantic representation of a letter string, but in the lexical decision task, this is not a requirement. Thus, it is not clear whether pseudohomophones activate semantics in the lexical decision task, and it is entirely possible that the pseudohomophone disadvantage could be attributable to a nonsemantic locus.

To investigate whether the pseudohomophone effect in the lexical decision task can be attributed to semantic characteristics of the base word, we need to examine lexical decisions for pseudohomophones that vary on some semantic dimension known to affect responses to their corresponding base words. If a pseudohomophone activates the semantic representation of its base word, then recognition of pseudohomophonesshould be influenced by base word characteristics. In the experiments reported here, we used the size of a word's semantic neighborhood as a measure of how richly the word is represented at the semantic level. As a measure of the semantic neighborhood size of a word, we chose to use set size, which Nelson, Schreiber, and McEvoy (1992) derived by giving participants words and having them list the first word that came to mind for each (Schreiber \& Carter, in press); the responses were then summed to give a measure of the semantic neighborhood size of a word. Words with many associates (e.g., movie) can thus be identified as having large semantic neighborhoods, whereas small-neighborhood words are those with relatively few associates (e.g., $d o g$ ). Previous research has shown that in a lexical decision task, words with large semantic neighborhoods are responded to more rapidly than words with sparse semantic neighborhoods(Buchanan, Westbury, \& Burgess, 2001; Locker, Simpson, \& Yates, 2003).

According to the interactive framework discussed above, words with larger semantic neighborhoods are responded to faster because activation at the semantic level is strong, and this enhanced activation feeds back to the orthographic level and helps participants respond more quickly to these words than to words with weaker activation from the semantic level (for a similar account of the ambiguity effect in lexical decision, see Pexman \& Lupker, 1999). Consequently, as semantic neighborhood size increases, "yes" latencies decrease. On the other hand, if pseudohomophones activate the semantic representation of their base words in the lexical decision task, then, as semantic neighborhood size increases, "no" la- tencies to pseudohomophones should increase. These predictions were tested in Experiment 1.

\section{EXPERIMENT 1}

\section{Method}

Participants. The participants were 58 undergraduates at the University of Kansas who received course credit for their participation. All were native speakers of English and reported having normal or corrected-to-normal vision. Three were not included in the analysis because their error rates in the lexical decision task were greater than $15 \%$, and another participant was excluded from the analyses for producing lexical decisions that were inordinately long. Therefore, the analyses reported below are based on the data of 54 participants.

Materials. Sixty four-letter stimuli were formed by crossing the two variables of letter string type (word or pseudohomophone) and semantic neighborhood size (large or small), resulting in 15 stimuli per condition. The stimuli were controlled for printed frequency (Kučera \& Francis, 1967), summed bigram frequency (Massaro, Taylor, Venezky, Jastrzembski, \& Lucas, 1980), concreteness (MRC Psycholinguistic Database, 2000), and orthographic neighborhood size (i.e., Coltheart's $N$ ). For the pseudohomophones, the values for printed frequency and concreteness were based on their respective base words. In addition to these variables, we also controlled for network connectivity (Nelson, Bennett, Gee, \& Schreiber, 1993). This measure reflects the number of connections among the members of a word's semantic neighborhood. If a word has a high connectivity value, there are many connections among the words that constitute the semantic neighborhood. Because Locker et al. (2003) found that connectivity affects latencies to words in a lexical decision task, this variable was controlled in the present research. As with frequency and concreteness, the values for the connectivity of pseudohomophones were based on their base words. Separate analyses of variance (ANOVAs) comparing the four groups on each of these control variables were conducted. These tests revealed that none of the groups differed significantly from the others on any of the control variables ( $p>.10$ for all analyses). Values for these control variables and semantic neighborhood can be found in Table 1. The stimuli and latencies from Experiment 1 are shown in Appendix A.

Finally, the stimuli were controlled on the visual similarity between the two groups of pseudohomophones and their respective base words, using three separate measures. First, the pseudohomophones in the two groups did not differ in the gross number of letters (i.e., the number of letters irrespective of position) that were shared between the pseudohomophone and the base word. Second, we controlled the two conditions on the number of position-specific letters that were common between pseudohomophones and base words. Finally, we verif ied that the two groups of pseudohomophones did not differ on Van Orden's orthographic similarity (OS) score (Van Orden, 1987). In this case, OS was calculated between each pseudohomophone and its base word. For all three of these measures, we conducted separate $t$ tests to compare the two groups of pseudohomophones. The results of these tests reveal that the two groups were tightly controlled on visual similarity between the pseudohomophone and the base word (all $p s>.10$ ). Finally, Vanhoy and Van Orden (2001) have demonstrated that processing of pseudohomophones can be affected by whether they contain an extant word body. Thus, we obtained all words with a Kučera and Francis frequency of at least one that shared a body with one of the pseudohomophones. Comparing the two groups of pseudohomophones revealed that they did not differ in terms of the number of words that share an extant body $(p>.10)$.

Procedure. The stimuli were shown on an IBM-compatible computer running Micro Experimental Laboratory software (Schneider, 
Table 1

Means and Standard Deviations for the Control Variables from Experiment 1

\begin{tabular}{|c|c|c|c|c|c|c|c|c|}
\hline \multirow[b]{3}{*}{ Control Variables } & \multicolumn{4}{|c|}{ Large Neighborhood } & \multicolumn{4}{|c|}{ Small Neighborhood } \\
\hline & \multicolumn{2}{|c|}{ Word } & \multicolumn{2}{|c|}{ Pseudohomophones } & \multicolumn{2}{|c|}{ Word } & \multicolumn{2}{|c|}{ Pseudohomophones } \\
\hline & $M$ & $S D$ & $M$ & $S D$ & $M$ & $S D$ & $M$ & $S D$ \\
\hline Frequency & 32 & 23 & 32 & 30 & 23 & 22 & 24 & 26 \\
\hline$N$ & 7 & 5 & 6 & 3 & 7 & 4 & 5 & 4 \\
\hline Bigram & 4,558 & 2,534 & 3,373 & 2,440 & 4,582 & 3,719 & 3,470 & 1,650 \\
\hline Concreteness & 520 & 105 & 519 & 110 & 485 & 93 & 551 & 74 \\
\hline Connectivity & 1.6 & 0.5 & 1.6 & 0.7 & 1.4 & 0.6 & 1.2 & 0.8 \\
\hline Semantic neighborhood & 24 & 2.4 & 22 & 2.7 & 6 & 3.2 & 8 & 2.9 \\
\hline
\end{tabular}

Note-Frequency $=$ printed frequency. $N=$ Coltheart's $N$, orthographic neighborhood size. Bigram $=$ summed bigram frequency. Concreteness is per the MRC Psycholinguistic Database. Connectivity = network connectivity.

1988). The participants were instructed to respond as quickly as possible, but to be careful not to make many mistakes. Before viewing the experimental stimuli, the participants performed lexical decisions on 30 practice stimuli consisting of equal numbers of words and pseudohomophones, none of which were used as experimental stimuli. To initiate the experiment, the participant pressed the space bar. Each trial consisted of a blank screen for $250 \mathrm{msec}$ that was followed by a fixation stimulus (plus sign) in the middle of the screen that lasted for $750 \mathrm{msec}$. Immediately following the offset of the fixation stimulus, a word or pseudohomophone was shown in lowercase. The stimulus remained on the screen until the participant responded by pressing one of the two response keys. Half of the participants responded "yes" to words by pressing the "A" key with the left index finger and responded "no" to pseudohomophones by pressing "L" with the right index finger. For the other half of the participants, these responses were reversed. The order of presentation of stimuli was randomly determined for each participant.

\section{Results and Discussion}

Mean lexical decision latencies and error rates are shown in Table 2. Outliers were defined as responses that were less than $250 \mathrm{msec}$ or greater than $2,000 \mathrm{msec}$. Outliers defined in this manner represented $0.28 \%$ of the data and were not included in any analyses. Also, although the means for each condition did not differ significantly on the connectivity measure, there was considerable variability for connectivity within each condition. In order to remove this variability, we included connectivity as a covariate in the items analysis.

A 2 (letter string type: word vs. pseudohomophone) $\times$ 2 (semantic neighborhood size: large vs. small) repeated measures ANOVA was conducted on response times by participants, and an ANCOVA with both variables as between-items factors and connectivity as a covariate was performed by items. The main effect of wordness was significant by participants $\left[F_{1}(1,53)=26.95, p<\right.$ $.001]$ and approached significance by items $\left[F_{2}(1,55)=\right.$ $3.52, p<.07]$. The main effect of semantic neighborhood was not significant by participants or items (both $F_{\mathrm{S}}<1$ ). However, both of these main effects were qualified by an interaction that was significant by participants $\left[F_{1}(1,53)=\right.$ $23.09, p<.001]$ and that approached significance by items $\left[F_{2}(1,55)=2.86, p<.10\right]$. Planned comparisons revealed that responses to words that had large semantic neighborhoods were faster than those to words with small semantic neighborhoods $\left[F_{1}(1,53)=12.43, p<\right.$ $\left..01 ; F_{2}(1,27)=4.43, p<.05\right]$. Conversely, response times were slower to pseudohomophones that had base words with large semantic neighborhoods than to pseudohomophones with small-neighborhood base words $\left[F_{1}(1,53)=\right.$ $\left.8.60, p<.01 ; F_{2}(1,27)=2.17, p>.10\right]$.

In the analysis of error rates, the main effect of letterstring type was significant by participants $\left[F_{1}(1,53)=\right.$ $6.71, p<.05]$, but not items $\left[F_{2}(1,55)=1.15, p>.10\right]$. The main effect of semantic neighborhood was not significant (both $F \mathrm{~s}<1$ ). Importantly, the predicted interaction of letter string type and semantic neighborhood size was significant by participants $\left[F_{1}(1,53)=16.60\right.$, $\left.p<.001 ; F_{2}(1,55)=3.04, p<.09\right]$. Congruent with the latency analysis, more errors were made to small- than to large-neighborhood words $\left[F_{1}(1,53)=9.44, p<.01\right.$; $\left.F_{2}(1,27)=3.41, p<.08\right]$. However, for pseudohomophones, the effect of semantic neighborhood size was reversed, with more errors made to large- than to smallneighborhood pseudohomophones $\left[F_{1}(1,53)=12.60\right.$, $\left.p<.01 ; F_{2}(1,27)=2.82, p<.11\right]$.

The results from Experiment 1 replicate previous findings showing that words with larger semantic neighborhoods are responded to faster than words with smaller semantic neighborhoods (Buchanan et al., 2001; Locker et al., 2003). In addition, these results demonstrate that pseudohomophones are able to activate the semantic representation of their respective base words in a lexical decision task. However, because activating the semantic representation of the base word of a pseudohomophone may be taken as evidence that the stimulus is a word, the effects of semantic neighborhood size are reversed in pseudohomophones. Thus, the slower lexical decision

Table 2

Lexical Decision Latencies (in Milliseconds), Standard Deviations, and Percentage Error Rates for the Words and Pseudohomophones From Experiment 1

\begin{tabular}{|c|c|c|c|c|c|c|}
\hline \multirow[b]{2}{*}{ Stimuli } & \multicolumn{3}{|c|}{ Large Neighborhood } & \multicolumn{3}{|c|}{$\underline{\text { Small Neighborhood }}$} \\
\hline & RT & $S D$ & $\% \mathrm{E}$ & RT & $S D$ & $\% \mathrm{E}$ \\
\hline Words & 609 & 107 & 4.6 & 645 & 120 & 8.1 \\
\hline Pseudohomophones & 689 & 121 & 5.4 & 658 & 100 & 2.6 \\
\hline
\end{tabular}


times to pseudohomophones are not just a function of a shared phonologicalcode between the pseudohomophone and its base word. Instead, these results suggest that slower processing of pseudohomophones is attributable, at least in part, to the semantic representation activated by a pseudohomophone.

One potential problem with Experiment 1 was that it did not include orthographically matched controls (i.e., nonwords orthographically similar to, but not homophonic with, the base word). By including orthographically matched controls, one could eliminate the possibility that the results of Experiment 1 might be attributable to orthographic, rather than phonological, factors.

\section{EXPERIMENT 2}

Experiment 2 had two goals. The first was to examine whether the apparent effect of semantic neighborhood size on the processing of pseudohomophones in Experiment 1 was a function of the pseudohomophones' orthography, not their phonology. That is, the pseudohomophonesmight have accessed the semantic representations of their base words through orthography and not phonology. According to this account, phonology should have nothing to do with activating the semantic representation of the base word. To evaluate this alternative explanation, we included orthographic controls in Experiment 2. Following the results of Experiment 1, we expected pseudohomophones with base words having large semantic neighborhoods to be responded to more slowly than pseudohomophones with base words having small semantic neighborhoods. However, we predicted that semantic neighborhood size would have no effect on responses to the control pseudowords, because these stimuli did not share a phonological code with the base word.

Including pseudowords offered the opportunity to test another effect often studied in relation to pseudohomophones-that is, how latencies to words differ as a function of foil type (James, 1975; Pugh, Rexer, \& Katz, 1994; Stone \& Van Orden, 1993). For example, Stone and Van Orden showed that the word-frequency effect was larger in the presence of pseudohomophones than in the presence of pseudowords. Thus, a second purpose of Experiment 2 was to investigate the semantic neighborhood effect for words as a function of foil type.

One account of why foil type affects word responses is that when presented with pseudohomophones, participants attenuate phonologically mediated access to the lexicon (Pugh et al., 1994). But such a strategy seems to be contradicted by the results of Experiment 1 . Specifically, if phonologically mediated access does not occur in the presence of pseudohomophones, one would not expect semantic neighborhood size to affect the processing of pseudohomophones themselves, because pseudohomophones should only be able to fully access the semantics of their base words through phonology. Yet this reasoning hinges on the assumption that in Experiment 1 the effect of semantic neighborhood for pseudo- homophones was due to shared phonology and not orthography. This assumption was tested by the inclusion of the orthographic controls in Experiment 2.

However, there is some evidence that phonological assembly may occur even when pseudohomophones are used as foils. Gibbs and Van Orden (1998) found a consistency effect when pseudohomophones were used as foils, although Pugh et al. (1994) failed to find a similar effect. Finally, Berent (1997) found a consistency effect in the presence of pseudohomophones in errors though not in reaction times. Thus, support for phonological assembly in the presence of pseudohomophones is equivocal.

In Experiment 2, we manipulated foil type as a betweenparticipants factor. The same words were used in the presence of both foil types, resulting in an ideal strategy manipulation (Stone \& Van Orden, 1993). Because pseudohomophones are more wordlike than pseudowords, lexical decisions should be more difficult in the presence of pseudohomophones(Van Orden \& Goldinger, 1994). Thus, anything indicating that the letter string is a word, such as its semantic representation accessed via orthography, should be more influential in the presence of pseudohomophones versus pseudowords. On this account, we predicted that the semantic neighborhood effect for words would be larger in the presence of pseudohomophones than in the presence of pseudowords. Most importantly, if we should also find an effect of semantic neighborhood for the pseudohomophones themselves but not for the control pseudowords, then the effect of foil type would not be attributable to participants' ignoring phonologically mediated representations.

\section{Method}

Participants. Participants were 105 undergraduates at the University of Kansas that received course credit for their participation. All participants were native speakers of English and reported having normal or corrected-to-normal vision. Five participants were not included in the analysis because their error rates in the lexical decision task were greater than $15 \%$. Therefore, the analyses reported below are based on the data of 100 participants.

Materials. Most of the stimuli used in Experiment 1 were also used in Experiment 2. However, with inclusion of the control pseudowords, 13 of the stimuli from Experiment 1 were replaced in order to equate the group item means on the control variables. The orthographic control stimuli were pronounceable pseudowords that were matched to the two groups of pseudohomophones. Thus, one set of control pseudowords was derived from words that had large semantic neighborhoods, and one was based on words with sparse semantic neighborhoods. All stimuli consisted of four letters and were presented in lowercase. The stimuli and latencies for Experiment 2 can be found in Appendix B.

All stimuli, including the orthographic control pseudowords, were controlled for printed frequency (Kučera \& Francis, 1967), summed bigram frequency (Massaro et al., 1980), concreteness (MRC Psycholinguistic Database, 2000), connectivity (Nelson et al., 1993), and orthographic neighborhood size. For the pseudohomophones and their control pseudowords, the values for printed frequency, connectivity, and concreteness were based on their respective base words. Separate ANOVAs for each of the control variables revealed that none of the groups differed significantly from each other (all $p s>.10$ ). A list of the means and standard deviations for these control variables and semantic neighborhood can be found in Table 3. 
Table 3

Means and Standard Deviations for the Control Variables from Experiment 2

\begin{tabular}{|c|c|c|c|c|c|c|c|c|c|c|c|c|}
\hline \multirow[b]{3}{*}{ Control Variables } & \multicolumn{6}{|c|}{ Large Neighborhood } & \multicolumn{6}{|c|}{ Small Neighborhood } \\
\hline & \multicolumn{2}{|c|}{ Word } & \multicolumn{2}{|c|}{ PHs } & \multicolumn{2}{|c|}{ PWs } & \multicolumn{2}{|c|}{ Word } & \multicolumn{2}{|c|}{ PHs } & \multicolumn{2}{|c|}{ PWs } \\
\hline & $M$ & $S D$ & $M$ & $S D$ & $M$ & $S D$ & $M$ & $S D$ & $M$ & $S D$ & $M$ & $S D$ \\
\hline Frequency & 27 & 15 & 26 & 25 & 26 & 25 & 20 & 23 & 23 & 26 & 23 & 26 \\
\hline$N$ & 7 & 4 & 6 & 3 & 5 & 3 & 5 & 3 & 5 & 3 & 6 & 5 \\
\hline Bigram & 5,160 & 2,912 & 3,187 & 2,565 & 3,171 & 2,033 & 4,934 & 4,307 & 3,407 & 1,743 & 3,771 & 1,696 \\
\hline Concreteness & 521 & 104 & 540 & 98 & 540 & 98 & 493 & 94 & 553 & 75 & 553 & 75 \\
\hline Connectivity & 1.6 & 0.5 & 1.6 & 0.7 & 1.6 & 0.7 & 1.4 & 0.6 & 1.2 & 0.8 & 1.2 & 0.8 \\
\hline Semantic neighborhood & 24 & 2.0 & 22 & 2.6 & 22 & 2.6 & 5 & 2.6 & 8 & 2.8 & 8 & 2.8 \\
\hline
\end{tabular}

Note-For key to variables, see Table 1 and text. PH, pseudohomophone; PW, pseudoword.

Visual similarity between pseudohomophones and pseudowords, and between each of these and their respective base words, was controlled using the measures described in Experiment 1 (i.e., Van Orden's OS measure, gross number of letters, and position-specific letters). The results of all of these comparisons reveal that the pseudohomophones and pseudowords were equated in terms of their visual similarity to each other and to their base words (all $p \mathrm{~s}>$ .10). Finally, the pseudohomophones did not differ in terms of extant word bodies $(p>.10)$.

Procedure. Half of the participants were randomly assigned to the control condition that had the pseudowords as foils. The other half of the participants saw the same words as those in the control condition, but the foils consisted of pseudohomophones. Otherwise, the procedure was the same as that in Experiment 1.

\section{Results and Discussion}

Mean lexical decision latencies and error rates are shown in Table 4. Outliers were defined as in Experiment 1 , resulting in the removal of $0.13 \%$ of the data. Analyses were performed by participants and by items. Also, as in Experiment 1, connectivity served as a covariate in the items analyses.

The effects of semantic neighborhood size on the processing of nonwords. To assess the impact of semantic neighborhood on the processing of nonwords, we conducted an ANOVA with nonword type (pseudohomophone vs. pseudoword) and semantic neighborhood size (large vs. small) as factors. For the participants analysis, nonword type was between participants and semantic neighborhood size was a repeated measure. For the items analysis, both factors were between-items factors. The results indicate that the main effect of nonword type was nonsignificant (both $F_{\mathrm{s}}<1$ ). The main effect of semantic neighborhood size was significant by participants $\left[F_{1}(1,98)=14.24\right.$, $p<.001]$, but failed to reach significance by items $\left[F_{2}(1,55)=2.23, p>.10\right]$. Finally, the interaction of interest was significant by participants $\left[F_{1}(1,98)=16.32\right.$, $p<.001]$ but failed to approach significance by items $\left[F_{2}(1,55)=1.98, p>.10\right]$. Planned comparisons of the interaction revealed that the effects of semantic neighborhood size were significant for pseudohomophones $\left[F_{1}(1,49)=32.67, p<.001 ; F_{2}(1,27)=4.37, p<.05\right]$. However, the same comparisons for the control pseudowords failed to indicate a reliable difference (both $F_{\mathrm{S}}<1$ ).

The error analysis revealed that the main effect of nonword type was significant by participants $\left[F_{1}(1,98)=\right.$
$4.95, p<.05]$ but was nonsignificant by items $\left[F_{2}(1,55)=\right.$ $2.20, p>.10]$. The main effect of semantic neighborhood yielded an $F<1$ for both the participants and items analyses. The interaction approached significance in the participants analysis $[F(1,98)=3.28, p<.08]$ but was nonsignificant in the items analysis $(F<1)$. Planned comparisons of the interaction revealed that more errors were made to pseudohomophones that had large semantic neighborhoods rather than small semantic neighborhoods $\left[F_{1}(1,49)=6.04, p<.05 ; F_{2}(1,27)=3.03, p<.10\right]$. However, there were no significant differences between the control pseudowords in terms of errors (both $F_{\mathrm{S}}<1$ ).

Effect of filler type. The following analyses tested whether the effects of semantic neighborhood size would be greater when words were embedded in pseudohomophones than in pseudowords. A 2 (semantic neighborhood size: large vs. small) $\times 2$ (foil type: pseudohomophone vs. pseudoword) ANOVA with connectivity as a covariate in the items analy sis yielded a significant main effect of semantic neighborhood size $\left[F_{1}(1,98)=44.01\right.$, $\left.p<.01 ; F_{2}(1,27)=5.94, p<.05\right]$. The main effect of foil type failed to prove significant in both the participants analysis and the items analysis (both $p$ s $>.10$ ). Importantly, the interaction was significant in both the participants analysis $\left[F_{1}(1,98)=8.23, p<.01\right]$ and the items analysis $\left[F_{2}(1,27)=8.13, p<.01\right]$. The effects of semantic neighborhood size were more pronounced when the foils were pseudohomophones $(51 \mathrm{msec})$ than when they were pseudowords $(20 \mathrm{msec})$.

Table 4

Lexical Decision Latencies (in Milliseconds), Standard Deviations, and Percentage Error Rates for the Stimuli From Experiment 2

\begin{tabular}{|c|c|c|c|c|c|c|}
\hline \multirow[b]{2}{*}{ Stimuli } & \multicolumn{3}{|c|}{ Large Neighborhood } & \multicolumn{3}{|c|}{ Small Neighborhood } \\
\hline & RT & $S D$ & $\% \mathrm{E}$ & RT & $S D$ & $\% \mathrm{E}$ \\
\hline \multicolumn{7}{|c|}{ Words and Pseudohomophone Foils } \\
\hline Words & 586 & 86 & 3.3 & 637 & 110 & 8.8 \\
\hline PHs & 687 & 128 & 6.0 & 652 & 132 & 4.0 \\
\hline \multicolumn{7}{|c|}{ Words and Pseudoword Foils } \\
\hline Words & 575 & 84 & 1.5 & 595 & 69 & 6.1 \\
\hline PWs & 668 & 105 & 6.9 & 669 & 108 & 7.7 \\
\hline
\end{tabular}

Note-PH, pseudohomophone; PW, pseudoword control. 
The error analyses revealed that the main effect of filler type was significant by participants $\left[F_{1}(1,98)=\right.$ $5.86, p<.05]$, but nonsignificant by items $(F<1)$. The main effect of semantic neighborhood size was significant by participants $\left[F_{1}(1,98)=41.05, p<.01\right]$ and by items $\left[F_{2}(1,27)=6.96, p<.05\right]$. The results of the error analysis failed to demonstrate a significant interaction (both $F$ s $<1$ ).

Finally, in both Experiments 1 and 2, several items analyses failed to reach significance. We believe that these nonsignificant effects are attributable to decreased power. In the present experiments, we were very concerned with controlling for multiple variables. Unfortunately, this severely limited the words available in each cell, compromising the power of the design. However, we do note that many of the items effects, including the more important effects for the conclusions drawn here, are significant despite this lack of power. ${ }^{1}$

The results of Experiment 2 provide strong evidence that the semantic representation of the base word of a pseudohomophone does affect processing of that pseudohomophone. Because semantic neighborhood size affected processing of the pseudohomophones but not orthographic control pseudowords, we conclude that access to this semantic representation was made through the shared phonology of the pseudohomophone and its respective base word. In addition, the results of Experiment 2 show that the effect of semantic neighborhood size on the processing of words is differentially affected by the foil type. When the foils are pseudohomophones, semantic neighborhood size has a larger effect on word responses than it does when the foils are simply pronounceable pseudowords. Moreover, this effect of foil type cannot be attributed to a strategy whereby phonologically mediated representations are ignored in the presence of pseudohomophones. If phonologically mediated access did not occur in the presence of pseudohomophones, we should not have obtained an effect of semantic neighborhood on the processing of pseudohomophones. Thus, these results and those of other studies (e.g., Gibbs \& Van Orden, 1998) provide converging evidence that the presence of pseudohomophones in the lexical decision task does not eliminate the use of assembled phonology. This is interesting because the use of assembled phonology should actually hurt performance when the foils are pseudohomophones. The finding that assembled phonology is computed even when it can be detrimental to performance seems to indicate that phonology plays an important role in visual word perception.

One point that should be noted regarding Experiment 2 is related to the failure to find a difference between the latencies to pseudohomophones and those to their control pseudowords. In fact, the error analysis shows that more errors were made to the pseudowords than to the pseudohomophones. However, closer inspection of the error rates to the individual items reveals that the error rates to the putative control pseudowords gank and pone were quite large (i.e., greater than 20\%). Unfortunately, it turns out that the stimulus pone is actually a word and the letter string gank is a slang word meaning "to steal." Thus, in both cases, these error rates may be misleading. In the case of pone, people who classified it as a word were actually correct. In regard to gank, some participants may have thought that this slang word was actually proper English. It appears that the difference between pseudohomophones and pseudowords in terms of error rates can be explained by these two unusual items. Nevertheless, this still does not explain why participants did not actually make more errors to pseudohomophones. Furthermore, it is puzzling that participants did not take longer to respond to pseudohomophones than to pseudowords, a result that has been obtained in many previous studies. However, we do note that in the present study, a pseudohomophone effect was obtained in terms of an effect of foil type. That is, the semantic neighborhood effect in words was more pronounced when the pseudohomophones, rather than pseudowords, served as foils. Nevertheless, it is worth considering why the reaction times to pseudohomophones and pseudowords did not differ. An inspection of the literature on the pseudohomophone effect reveals a crucial difference between our experiment and other experiments concerned with the pseudohomophone effect. Specifically, the researchers in past studies have presented both pseudohomophones and pseudowords in mixed blocks (Besner \& Davelaar, 1983; Goswami, Ziegler, Dalton, \& Schneider, 2001; Mayall \& Humphreys, 1996; McCann et al., 1988; Pring, 1981; Seidenberg et al., 1996; Underwood, Roberts, \& Thomason, 1988; Vanhoy \& Van Orden, 2001). That is, pseudohomophones and pseudowords were intermixed and both were seen by the participants. However, in the research reported here, the pseudohomophones and pseudowords were presented in pure blocks. Participants saw only pseudohomophones or pseudowords, but not both. This was necessary to allow us to compare the effect of semantic neighborhood size on words embedded within the two different types of nonwords. We believe that our failure to obtain a difference between lexical decision latencies to pseudohomophones as opposed to pseudowords may be attributable to this difference in methodology.

Some indication that this may be true comes from the recent work of Borowsky, Owen, and Masson (2002), who looked at the difference in naming latencies to pseudohomophones and pseudowords presented in pure versus mixed blocks. The important point here is that their results indicate that the naming latencies to these types of nonwords actually changed on the basis of whether participants read a list of mixed pseudohomophones and pseudowords versus reading a list of one type of nonword presented in a pure block followed by the other type of nonword presented in a pure block. However, there are two important distinctions between the Borowsky et al. study and the research reported here. 
First, they used a naming task, rather than a lexical decision task. Second, their participants saw pure blocks of both types of stimuli. In our study, participants saw pure blocks of only one type of nonword. Despite these differences, the Borowsky et al. study shows that the pseudohomophone effect can change as a function of whether the stimuli are presented in pure or in mixed blocks. In fact, under some circumstances, they found that the pseudohomophone effect actually reversed. Thus, we believe that our failure to obtain a difference between pseudohomophones and pseudowords may be attributable to the fact that we presented our nonwords in pure blocks, rather than with the mixed-block procedure used in prior pseudohomophone studies. Nonetheless, this should not undermine the conclusion that pseudohomophones with large semantic neighborhoods are responded to more slowly than those with small semantic neighborhoods. Because we found a semantic neighborhood effect for pseudohomophones and not for their orthographically matched controls, we can conclude that the pseudohomophones were able to access the semantic representation of their base words via phonology. If the effect were due to the orthographic overlap of the pseudohomophones and their base words, we should have seen a similar effect for the control pseudowords, which we did not (i.e., the mean difference was only $1 \mathrm{msec}$ ).

Accounting for frequency. Although the words used in the present experiment were controlled on frequency as measured by Kučera and Francis (1967), a significant difference was subsequently discovered between the two groups of words used in Experiment 1 in terms of the frequency norms of Carroll, Davies, and Richman (1971). However, it is important to note that the frequency of the base words for pseudohomophones did not differ. To ensure that frequency was not a factor in explaining our results regarding the word stimuli, we reexamined the items analysis from Experiment 1, comparing words with large semantic neighborhoods versus those with small semantic neighborhoods. In this items analysis, frequency according to Carroll et al., Kučera and Francis, and CELEX (Baayen, Piepenbrock, \& Gulikers, 1995) were all used as covariates, to remove the variability attributable to frequency as measured by three separate sets of norms. For Experiment 1, this analysis did decrease the impact of the neighborhood size variable, which was rendered nonsignificant for both latencies and errors, suggesting that the semantic neighborhood effect for words in Experiment 1 may have been partially due to a confound with frequency. A similar items analysis performed on the data from Experiment 2, however, revealed that in the presence of pseudohomophone foils, the semantic neighborhood effect was still significant in both latencies and error rates $[F(1,24)=4.78, p<.05$, and $F(1,24)=4.87, p<.05$, respectively]. For the words embedded in pseudowords, the effect was nonsignificant for latencies $[F(1,24)=1.07, p>.10]$ and approached significance in the error analysis $[F(1,24)=3.15, p<$ $.09]$. As further evidence that the semantic neighborhood effect was not attributable to a confound with frequency, we noted that the $F$ values for both the CELEX and Carroll et al. frequency covariates was less than one in all analyses from Experiment 2 . In fact, the only frequency covariate that was significant in any of the analyses was the Kučera and Francis frequency covariate. However, recall that the words were controlled and never differed significantly in terms of Kučera and Francis frequency. The results from Experiment 2 are reassuring in showing that the effect of semantic neighborhood for words remains when variability attributable to frequency, as measured by three separate sets of norms, is removed from the dependent measures, which replicates previous research (Buchanan et al., 2001; Locker et al., 2003).

\section{GENERAL DISCUSSION}

The results of Experiments 1 and 2 support the hypothesis that the processing of pseudohomophones is affected by the semantic representation of the base words from which they are derived. These results can be readily understood in terms of a distributed model that has representations at the orthographic, phonological, and semantic levels, with bidirectional connections existing among all levels (e.g., Pexman \& Lupker, 1999). A model of this type is fully interactive in that information is shared among all levels in the system. In a distributed model such as this, one way in which the lexical decision task could be performed is based on how quickly the orthographic units settle. If the orthographic units reach an acceptable degree of stability, then the system can respond "yes." However, we assume that the amount of settling that is required in order to indicate that the stimulus is a word can vary. That is, in some instances, a greater degree of settling is required in order to indicate that the letter string is a word. Thus, we believe that there is a continuum of settling, and exactly how much settling is required in order to respond "yes" is a direct function of the environment in which the words are presented. When the words are embedded within wordlike nonwords (e.g., pseudohomophones), a greater degree of settling is required for words to be distinguished from nonwords. A very similar account of foil effects is given by Borowsky and Masson (1996). Using a connectionist model, Borowsky and Masson simulated lexical decisions based on the energy in a Hopfield network. Energy gives a measure of the familiarity of the stimulus. Borowsky and Masson had the network respond "yes" as soon as some minimum amount of energy was obtained. The important relationship to the present work is that the minimum amount of energy differed as a function of foil type. When the foils were more wordlike, the minimum energy criterion was increased. Similarly, in the present model, we propose that when the foils are more wordlike, as in the 
case of pseudohomophones, a greater degree of settling is required.

Regarding nonwords, if the units have still not reached an acceptable degree of stability after some amount of time, then the system responds "no." However, a deadline alone is too simplistic to give an accurate account of differences in processing between groups of nonwords. That is, if nonword responses are based solely on a deadline, then the responses to pseudohomophones varying in terms of semantic neighborhoods should not vary, but as our results show, they do vary. For this reason, and as will be explained in more detail below, we believe that the "no" response can be made early in processing (i.e., before the deadline) if the system is in a high state of instability.

The semantic neighborhood size effect for words can be understood in terms of the enhanced feedback from the semantic level to the orthographic level. The larger the semantic neighborhood of a word, the more richly it is represented at the semantic level, and consequently the pattern of activation from the semantic units to the orthographic units will be stronger than it would if the semantic neighborhood was small. This enhanced activation should cause the orthographic units to reach an acceptable level of stability more quickly.

The effects of semantic neighborhood size on the processing of pseudohomophones can be understood in a similar manner. However, in this case, strong activation at the semantic level is misleading. The strong pattern of activation passed from the semantic level to the orthographic level incorrectly indicates that the pseudohomophone is a word. This pattern of activation that is received by the orthographic units from the semantic units will specify a spelling pattern that does not match the actual input pattern. For example, the pseudohomophone boan will excite the semantic representation of bone through their shared phonology, but when the semantic representation for bone feeds activation to the orthographic level, this activation will specify bone as the correct orthographic pattern. Furthermore, feedback from the phonological units also indicates that the input was bone. A pseudohomophone that has a base word with a large semantic neighborhood results in a strong pattern of activation driving the orthographic units toward the attractor for its base word. The strong semantic activation coupled with the feedback pattern from phonology makes the pseudohomophone appear very wordlike. Yet the pseudohomophone receives disconfirming activation from its orthography, and for this reason, in most instances, it will never allow the system to obtain the degree of stability required for responding "yes." As a result, the system will respond "no" upon reaching the deadline for such a response. However, sometimes it does reach the level of stability indicating a word, which explains why more errors are made to pseudohomophones with large semantic neighborhoods. On the other hand, if the pseudohomophone has a base word with a small semantic neighborhood, the pattern of activation from the semantic units to the orthographic units is relatively weak. Thus, the system never gets close to settling in a state that is defined by the base word. In this case, it is not necessary to extend processing until the deadline is reached. Instead, the "no" response can be made before the deadline on the basis of the lack of any evidence that the letter string is a word.

The effects of foil type can be understood in terms of this type of model as well. As discussed above, we propose that the degree of settling that is required increases in the presence of pseudohomophones, because pseudohomophones are very wordlike and push the system toward a quasi-stable state defined by their base words. This is especially true for pseudohomophones with large semantic neighborhoods. Thus, to distinguish words from pseudohomophones, the system adopts a more stringent criterion (i.e., a higher degree of settling) to avoid incorrectly responding "yes" to a pseudohomophone. Because more settling is required, the latencies to words increase in the presence of pseudohomophones. The words that incur the greatest latency increase are those with small semantic neighborhoods. These words have weak semantic representations, so it takes considerably more time for them to reach an acceptable level of stability in the presence of pseudohomophones. However, latencies to words with rich semantic representations (i.e., with large semantic neighborhoods) do not increase as much because they are so strongly activated at the semantic level, and the additional settling that is required is rapidly obtained when a strong pattern of activation is fed from the semantic units to the orthographic units. This means that the effect of foil type will be more pronounced for words with small semantic neighborhoods, as the results show.

Although we have discussed the results in terms of a distributed model that is fully interconnected with lexical decisions taking place at the level of orthography, other models could account for these results as well. One particularly worth mentioning is Plaut's (1997) distributed model, which performs the lexical decision on the basis of semantic familiarity, defined by Plaut in terms of semantic stress. Plaut shows that words have larger semantic stress values than nonwords do, and the discrepancy between these stress values can be used as the basis for lexical decision: The system can respond "word" if the semantic stress value is large enough. Especially important for the present research is Plaut's attempt at modeling lexical decisions to pseudohomophones. Plaut showed that the semantic stress value for a pseudohomophone is affected by the base word's semantic representation, which is accessed by the phonology shared by the base word and the pseudohomophone. So, given Plaut's model, the effect of semantic neighborhood size on the processing of words could be explained by assuming that words with large semantic neighborhoods generate larger semantic stress values, resulting in shorter reaction times to these words. However, for pseudo- 
homophones, semantic stress incorrectly indicates that the pseudohomophone is a word. If pseudohomophones with large semantic neighborhoods generate larger semantic stress values than do pseudohomophones with smaller semantic neighborhoods, it naturally follows from the model that lexical decisions to pseudohomophones with large semantic neighborhoods should take longer than lexical decisions to pseudohomophones with smaller semantic neighborhoods. Thus Plaut's model seems to predict the present results. The major difference between the model discussed above and Plaut's is that we assume that lexical decisions take place at the level of orthography, an assumption held by other researchers as well (e.g., Pexman \& Lupker, 1999), whereas in Plaut's model, the lexical decision takes place within the semantic system. Our results do not adjudicate between these alternative accounts. However, these results do provide important constraints on models of visual word recognition by showing that pseudohomophones can access the semantic representation of their base words and that phonological processing in the presence of pseudohomophones is not eliminated.

\section{CONCLUSION}

The present results indicate that the processing of pseudohomophones is affected by the semantic representation of their base words. The pattern of this effect is opposite that of the semantic neighborhood effect in words. Using orthographic controls, we were able to conclude that the locus of this effect is phonological. Moreover, the results indicate that the effect of semantic neighborhood size in words is sensitive to foil type, and that this effect of foil type is not due to a de-emphasis in phonological recoding. Since semantics does influence the processing of pseudohomophones in the lexical decision task and the inclusion of pseudohomophones does not eliminate the use of assembled phonology, it should be a goal of future research to incorporate these findings into current computational models of visual word recognition.

\section{REFERENCES}

Batyen, R. H., Piepenbrock, R., \& Gulikers, L. (1995). The CELEX lexical database (CD-ROM). Philadelphia: University of Pennsylvania, Linguistic Data Consortium.

Berent, I. (1997). Phonological priming in the lexical decision task regularity effects are not necessary evidence for assembly. Journal of Experimental Psychology: Human Perception \& Performance, 23, 1727-1742.

Besner, D., \& Davelaar, E. (1983). Suedohomofoan effects in visual word recognition: Evidence for phonological processing. Canadian Journal of Psychology, 37, 300-305.

Borowsky, R., \& MAsson, M. E. J. (1996). Semantic ambiguity effects in word identification. Journal of Experimental Psychology: Learning, Memory, \& Cognition, 22, 63-85.

Borowsky, R., Owen, W. J., \& Masson, M. E. J. (2002) Diagnostics of phonological lexical processing: Pseudohomophone naming advantages, disadvantages, and base-word frequency effects. Memory \& Cognition, 30, 969-987.

Buchanan, L., Westbury, C., \& Burgess, C. (2001). Characterizing semantic space: Neighborhood effects in word recognition. Psychonomic Bulletin \& Review, 8, 531-544.

Carroll, J. B., Davies, P., \& Richman, B. (1971). American Heritage word frequency book. New York: Houghton Mifflin.

Coltheart, M., Davelaar, E., Jonasson, J., \& Besner, D. (1977). Access to the internal lexicon. In S. Dornic (Ed.), Attention and performance VI (pp. 535-555). Hillsdale, NJ: Erlbaum.

FERA, P., \& Besner, D. (1992). The process of lexical decision: More words about a parallel distributed processing model. Journal of Experimental Psychology: Learning, Memory, \& Cognition, 18, 749764.

GibBs, P., \& VAN Orden, G. C. (1998). Pathway selection's utility for control of word recognition. Journal of Experimental Psychology: Human Perception \& Performance, 24, 1162-1187.

Goswami, U., Ziegler, J. C., Dalton, L., \& Schneider, W. (2001). Pseudohomophone effects and phonological recoding procedures in reading development in English and German. Journal of Memory \& Language, 45, 648-664.

JAMES, C. T. (1975). The role of semantic information in lexical decisions. Journal of Experimental Psychology: Human Perception \& Performance, 1, 130-136.

KuČERA, H., \& Francis, N. (1967). Computationalanalysis of presentday American English. Providence, RI: Brown University Press.

Locker, L., JR., Simpson, G. B., \& Yates, M. (2003). Semantic neighborhood effects on the recognition of ambiguous words. Memory \& Cognition, 31, 505-515.

Massaro, D. W., Tay lor, G. A., Venezky, R. L., Jastrzembski, J. E., \& LUCAS, P. A. (1980). Letter and word perception: The role of orthographic structure and visual processing in reading. Amsterdam: North-Holland.

Mayall, K., \& Humphreys, G. W. (1996). Case mixing and the tasksensitive disruption of lexical processing. Journal of Experimental Psychology: Learning, Memory, \& Cognition, 22, 278-294.

McCann, R. S., Besner, D., \& DavelaAr, E. (1988). Word recognition and identification: Do word-frequency effects reflect lexical access? Journal of Experimental Psychology: Human Perception \& Performance, 14, 693-706.

MRC PSYChOLINGUIST IC DATABASE (2000). MRC psycholinguistic database: Machine usable dictionary. Version 2.00. Available at http://www. psy.uwa.edu.au/MRCDataBase/uwa_mrc.htm.

Nelson, D. L., Bennett, D. J., Gee, N. R., \& Schreiber, T. A. (1993). Implicit memory: Effects of network size and interconnectivity on cued recall. Journal of Experimental Psychology: Learning, Memory, \& Cognition, 19, 747-764.

Nelson, D. L., Schreiber, T. A., \& McEvoy, C. L. (1992). Processing implicit and explicit representations. Psychological Review, 99, 322348.

Pexman, P. M., \& Lupker, S. J. (1999). Ambiguity and visual word recognition: Can feedback explain both homophone and polysemy effects? Canadian Journal of Experimental Psychology, 53, 323-334.

Plaut, D. C. (1997). Structure and function in the lexical system: Insights from distributed models of word reading and lexical decision. Language \& Cognitive Processes, 12, 765-805.

PrING, L. (1981). Phonological codes and functional spelling units: Reality and implications. Perception \& Psychophysics, 30, 573-578.

Pugh, K. R., Rexer, K., \& Katz, L. (1994). Evidence of flexible coding in visual word recognition. Journal of Experimental Psychology: Human Perception \& Performance, 20, 807-825.

Rubenstein, H., Lewis, S. S., \& Rubenstein, M. A. (1971). Evidence for phonemic recoding in visual word recognition. Journal of Verbal Learning \& Verbal Behavior, 10, 645-657.

SCHNEIDER, W. (1988). Micro Experimental Laboratory: An integrated system for IBM PC compatibles. Behavior Research Methods, Instruments, \& Computers, 20, 206-217.

Schreiber, T. A., \& CARTER, K. (in press). The activation of preexisting associations in an episodic memory task. Memory.

Seidenberg, M. S., \& McClelland, J. L. (1989). A distributed, developmental model of word recognition and naming. Psychological Review, 96, 523-568.

Seidenberg, M. S., Petersen, A., MacDonald, M. C., \& Plaut, D. C. 
(1996). Pseudohomophone effects and models of word recognition. Journal of Experimental Psychology: Learning, Memory, \& Cognition, 22, 48-62.

SPSS FOR WINDOws (Release 11.5.0) [Computer Software] (2002). Chicago, IL: SPSS Inc.

Stone, G. O., \& Van Orden, G. C. (1993). Strategic control of processing in word recognition. Journal of Experimental Psychology: Human Perception \& Performance, 19, 744-774.

Underwood, G., Roberts, M., \& Thomason, H. (1988). Strategical invariance in lexical access: The reappearance of the pseudohomophone effect. Canadian Journal of Psychology, 42, 24-34.

VAnhoy, M., \& VAN Orden, G. C. (2001). Pseudohomophones and word recognition. Memory \& Cognition, 29, 522-529.

VAN ORden, G. C. (1987). A ROWS is a ROSE: Spelling, sound, and reading. Memory \& Cognition, 15, 181-198.

VAn Orden, G. C., \& Goldinger, S. D. (1994). Interdependence of form and function in cognitive systems explains perception of printed words. Journal of Experimental Psychology: Human Perception \& Performance, 20, 1269-1291.

Van Orden, G. C., Johnston, J. C., \& Hale, B. L. (1988). Word identification in reading proceeds from spelling to sound to meaning. Journal of Experimental Psychology: Learning, Memory, \& Cognition, 14, 371-386.

Ziegler, J. C., JACOBS, A. M., \& KLÜPPEL, D. (2001). Pseudohomophone effects in lexical decision: Still a challenge for current word recognition models. Journal of Experimental Psychology: Human Perception \& Performance, 27, 547-559.

\section{NOTE}

1. Another potential concern is that the crucial interactions in Experiment 1 (i.e., between letter string type and semantic neighborhood size) and Experiment 2 (i.e., between nonword type and semantic neighborhood size) were nonsignificant in the items analyses but were significant in the participants analyses. As we argue above, the power of the items analyses was limited. In fact, for the analyses of latencies, the observed power, calculated using SPSS (2002), was . 38 for the interaction in Experiment 1 and .28 in Experiment 2. The power for the error analyses was .40 in Experiment 1 and .14 in Experiment 2. Thus, it is clear that the power was quite low in the items analyses. However, another difference between the participants and the items analyses must be considered. Specifically, connectivity was used as a covariate in the items analyses, but not in the participants analyses. It is possible that the significant interactions for the participants analyses were due to connectivity and that when connectivity was removed from the items analyses, these interactions became nonsignificant. To ensure that this was not the case, we reanalyzed the two interactions for both latencies and error rates without using connectivity as a covariate. In all instances, the pattern of results did not change. Thus, it appears that our failure to obtain significant effects for these interactions in the items analyses was due to a lack of power.

Stimuli and Latencies From Experiment 1

\begin{tabular}{|c|c|c|c|}
\hline & & \multicolumn{2}{|c|}{ Pseudohomophones } \\
\hline \multicolumn{4}{|c|}{ Large Semantic Neighborhoods } \\
\hline bear & 626 & clae & 650 \\
\hline iron & 600 & lais & 614 \\
\hline card & 589 & raip & 668 \\
\hline crab & 609 & skar & 619 \\
\hline hang & 597 & sope & 787 \\
\hline bowl & 564 & $\operatorname{scin}$ & 614 \\
\hline warn & 712 & dair & 680 \\
\hline mole & 686 & burd & 743 \\
\hline wood & 535 & bloe & 656 \\
\hline bury & 750 & caip & 620 \\
\hline fair & 573 & jurk & 770 \\
\hline seal & 631 & durt & 783 \\
\hline tube & 587 & boan & 764 \\
\hline fish & 552 & wate & 815 \\
\hline grow & 571 & caik & 586 \\
\hline \multicolumn{4}{|c|}{ Small Semantic Neighborhoods } \\
\hline weep & 630 & nale & 799 \\
\hline cash & 553 & fule & 737 \\
\hline dumb & 578 & coyn & 583 \\
\hline text & 557 & coan & 702 \\
\hline male & 577 & rute & 761 \\
\hline seek & 576 & hiev & 579 \\
\hline halt & 683 & gane & 806 \\
\hline hose & 666 & sikk & 578 \\
\hline soil & 591 & banc & 594 \\
\hline slay & 763 & caiv & 626 \\
\hline brat & 756 & mele & 606 \\
\hline noun & 644 & mair & 633 \\
\hline lens & 696 & barc & 634 \\
\hline suds & 986 & croe & 653 \\
\hline aunt & 599 & $\operatorname{minc}$ & 607 \\
\hline
\end{tabular}


APPENDIX B

Stimuli and Latencies From Experiment 2

\begin{tabular}{|c|c|c|c|c|c|c|}
\hline Word & $\mathrm{RT}_{\mathrm{W}}(\mathrm{PH})$ & $\mathrm{RT}_{\mathrm{W}}(\mathrm{PW})$ & $\mathrm{PH}$ & RT & PW & RT \\
\hline \multicolumn{7}{|c|}{ Large Semantic Neighborhoods } \\
\hline rack & 609 & 613 & clae & 637 & claf & 657 \\
\hline iron & 580 & 566 & lais & 633 & larn & 712 \\
\hline card & 528 & 557 & raip & 688 & ralp & 658 \\
\hline soup & 566 & 568 & skar & 672 & snar & 668 \\
\hline hang & 565 & 568 & sope & 748 & solp & 625 \\
\hline bowl & 552 & 579 & $\operatorname{scin}$ & 634 & stin & 697 \\
\hline warn & 655 & 615 & dair & 803 & darp & 686 \\
\hline mole & 608 & 593 & burd & 739 & birf & 658 \\
\hline plug & 602 & 590 & bloe & 681 & blof & 579 \\
\hline rare & 685 & 606 & caip & 622 & calp & 675 \\
\hline beer & 543 & 516 & jurk & 769 & jark & 710 \\
\hline seal & 636 & 582 & durt & 771 & dort & 703 \\
\hline tube & 606 & 568 & boan & 730 & boln & 586 \\
\hline fish & 552 & 554 & krab & 636 & frab & 662 \\
\hline grow & 525 & 550 & caik & 612 & cark & 728 \\
\hline \multicolumn{7}{|c|}{ Small Semantic Neighborhoods } \\
\hline weep & 677 & 593 & nale & 770 & nalp & 610 \\
\hline cash & 554 & 527 & fual & 712 & fulm & 644 \\
\hline dumb & 603 & 569 & coyn & 629 & coln & 663 \\
\hline text & 554 & 531 & coan & 714 & cron & 648 \\
\hline wick & 667 & 609 & pyne & 662 & pone & 759 \\
\hline seek & 597 & 525 & hiav & 607 & hirv & 583 \\
\hline halt & 692 & 689 & gane & 771 & gank & 701 \\
\hline pony & 609 & 570 & sikk & 608 & sirk & 675 \\
\hline soil & 576 & 562 & banc & 660 & bant & 694 \\
\hline itch & 652 & 619 & caiv & 586 & cavy & 700 \\
\hline brat & 681 & 627 & mele & 611 & melp & 610 \\
\hline noun & 623 & 610 & mair & 640 & marn & 677 \\
\hline lens & 681 & 604 & barc & 631 & barg & 668 \\
\hline suds & 748 & 723 & croe & 605 & crot & 674 \\
\hline twig & 740 & 638 & $\operatorname{minc}$ & 606 & mins & 722 \\
\hline
\end{tabular}

Note- $\mathrm{PH}$, pseudohomophone; $\mathrm{PW}$, pseudoword control; RT, latency; $\mathrm{RT}_{\mathrm{W}}(\mathrm{PH})$, word latency for words embedded in pseudohomophones; $\mathrm{RT}_{\mathrm{W}}(\mathrm{PW})$, word latency for words embedded in control pseudowords.

(Manuscript received June 12, 2002;

revision accepted for publication May 8, 2003.) 